\title{
EL MITO DE LA LIBERTAD DE EXPRESIÓN EN LA CREACIÓN ARTÍSTICA
}

\author{
Domingo Lovera Parmo*
}

\begin{abstract}
RESUMEN
Las creaciones artísticas se ven expuestas corrientemente a embates judiciales. Se reclama que las creaciones afectan el honor de terceras personas e instituciones ( $v$. gr. la Iglesia), lo que ba llevado a nuestra jurisprudencia a tener que lidiar los alcances de la libertad de expresión en el arte. Este trabajo argumenta que los jueces han preferido centrarse en el mérito artístico de las obras antes que en los contornos de la libertad de expresión, cuestión que puede explicarse por la ausencia de una teoría política que justifique la misma.
\end{abstract}

\section{LIBERTAD DE EXPRESIÓN - CREACIÓN ARTÍSTICA - DISCURSO PÚBLICO}

\section{The myth of freedom of expression in artistic creations}

\begin{abstract}
Artistic creations regularly face judicial attacks. It is argued that artistic creations affect the honor of third parties and institutions (i.e. the Catholic Church), which has taken our jurisprudence to decide whether freedom of expression protects art. This work argues our judges, however, have preferred to devote themselves to the analysis of the artistic merits of questioned art, instead of defining the scope of the freedom of expression. This may be explained in the absence of a political theory about the values freedom of expression serves.
\end{abstract}

FREEDOM OF EXPRESSION - ARTISTIC CREATIONS - PUBLIC DISCOURSE

* Abogado, Máster en Derecho, Profesor de Derecho en la Universidad Diego Portales, Santiago de Chile, domingo.lovera@udp.cl. Agradezco los comentarios que Pedro Anguita, Jorge Contesse, Iñigo De la Maza, Claudio Nash y Tomás Vial formularan a una versión preliminar de este trabajo. Una segunda versión, igualmente preliminar, fue discutida en el Centro de Investigaciones Jurídicas de la Facultad de Derecho de la Universidad Diego Portales. En aquella oportunidad surgieron interesantes preguntas a las que ahora intento dar respuesta.

Artículo recibido el $1^{\circ}$ de febrero de 2010 y aceptado para su publicación por el Comité Editorial el 28 de mayo de 2010 . 
"Cuando dimos un concierto en un club juvenil católico, el tipo que estaba al mando no quiso pagarnos, afirmando que lo que nosotros hacíamos 'no era música.' Andrew y Peter acudieron a los tribunales, y para su total incredulidad y la nuestra, perdimos, y es que el magistrado, para nuestra decepción, estuvo de acuerdo con la opinión del director del club juvenil ...”.

Nick Mason, Dentro de Pink Floyd**

\section{INTRODUCCIÓN}

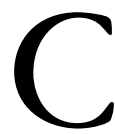

uando Jerome Frank se refería al 'mito judicial,' quería llamar la atención sobre la singular forma con la que los jueces describían su trabajo. Le molestaba que los jueces argumentaran que su labor consistía únicamente en aplicar el derecho, y no en crearlo. Frank, en cambio, creía que los jueces no lograban darse cuenta que formaban parte del mito de la profesión judicial: no eran capaces de ver más allá de su propia descripción de su labor y, por lo mismo, eran incapaces de poder entender que, ejerciendo sus funciones, hacían algo más (bastante más, la verdad) que 'solo aplicar el

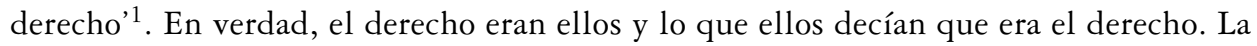
importancia de recordar las ideas de Jerome Frank, uno de los principales pensadores del realismo norteamericano, radica en que la razón para sostener el 'mito judicial' era el evitar asumir las terroríficas consecuencias que se siguen de aceptar esa realidad -que nos presenta jueces omnipotentes, y reglas que de poco sirven a la hora de controlar la discrecionalidad de éstos. Por eso preferimos negar esa realidad y, junto a los jueces, pasamos a formar parte del 'mito'2.

En materia de libertad de expresión y creación artística -tema sobre el que avanzaré algunas ideas en este trabajo- ocurre algo similar en algún sentido, y distinto en otro. Distinto, porque se trata de libertad de expresión y creación artística, no de jueces y su poder ${ }^{3}$. Y similar, en tanto la protección que una serie de casos ha recibido de las instancias decisorias ${ }^{4}$ en materia de libertad de creación artística es mucho más débil de lo que se cree. En esas decisiones veremos que la fuerza de la protección pareciera provenir de los mismos fundamentos que justifican la libertad de expresión. Pero ello ocurre solo en apariencia. Nuestras instancias decisorias en materia de libertad de creación artística

** Ediciones Robinbook, Barcelona, 2007, p. 42.

${ }^{1}$ Frank J., "Law and the Modern Mind", en Cerda, C. (ed.), Razonamiento Judicial, Universidad Diego Portales, Santiago, 1995, p. 254. Waldron ha señalado que los juristas se sienten más a gusto con esta descripción del trabajo judicial. Las razón para ello sería que si el Estado de derecho significa gobierno de las leyes (y no de los hombres) el parlamento y su funcionamiento aparece como "demasiado humano" frente a esa idea. Waldron, J., The Dignity of Legislation, Cambridge University Press, Cambridge, 1999, pp. 24-5.

${ }^{2}$ Frank, J., Derecho e Incertidumbre, Fontamara S.A., México D.F., 1991, p. 25.

${ }^{3}$ Aunque algo de eso, inevitablemente, hay.

${ }^{4}$ Prefiero utilizar la expresión instancias decisorias pues algunos de los casos que revisaré se han resuelto en instancias administrativas, distintas a los tribunales. 
han preferido evadir la fuerza que las ideas de la libertad de expresión poseen sobre la primera, creando, así, el mito de una protección que, justamente por prescindir de las fuertes conexiones con la libre expresión, es delicada y corre el riesgo de ser rápidamente desplazada.

Lo anterior no es irrelevante en el contexto nacional. La historia de la libertad de expresión en Chile ha sido, como el derecho, una de tensión ${ }^{5}$. Han existido avances en el plano normativo, qué duda cabe, pues hemos transitado desde leyes que proscribían partidos políticos ${ }^{6}$, a disposiciones constitucionales que prohíben la censura en materia de producción cinematográfica ${ }^{7}$. Pero se trata de una historia plagada de retrocesos en medio de esos (aparentes) progresos normativos, donde las expresiones artísticas se han visto particularmente afectadas ${ }^{8}$. Recientemente las situaciones de censura también han afectado al arte. Así, nuestra historia conoce de bandas de música que deben dar conciertos en el marco de una gira en el resto de Sudamérica, pero no en Chile9 ; películas cuya exhibición pública resulta prohibida por nuestras cortes bajo el argumento de “presentar la figura de Jesucristo ... de tal modo deformada, humillada, que su honra aparece vulnerada gravemente ..." ${ }^{10}$; libros investigativos sobre jueces ${ }^{11}$ y cantantes ${ }^{12}$ incautados en el marco de investigaciones criminales; y series de televisión cuyo estreno se aplazó y final editó a instancias de la Cancillería chilena -abogando por mantener tranquilas las relaciones diplomáticas ${ }^{13}$. En un contexto tal, no resulta extraño que un

${ }^{5}$ Ya en 1998 se daba cuenta de los problemas que existían en la transición chilena a la democracia a efectos de consagrar una teoría robusta de la libertad de expresión. Véase, Human Rights Watch, Los Límites de la Tolerancia: Libertad de Expresión y Debate Público en Chile, Lom Ediciones, Santiago, 1998.

${ }^{6}$ Huneeus, C., La Guerra Fría Chilena: Gabriel González Videla y la Ley Maldita, Editorial Debate, Santiago, 2009, especialmente pp. 197-245, donde se evidencia que sus detractores reclamaron la afectación de la libertad de expresión.

${ }^{7}$ Ley N 19.742 (D. Of. 25.08.2001), motivada por la decisión de la Corte Interamericana de Derechos Humanos en el caso de "La Última Tentación de Cristo". Costa Rica, 5 de febrero de 2001, Caso "La Última Tentación de Cristo” Vs. Chile, Serie C. N 73.

${ }^{8}$ Un completo análisis histórico en Vitale, L., Historia de la Censura en Chile, en Jones, D., Censorship: An Encyclopaedia, Fitzroy Dearborn Publishers, Londres, 2001. Referencias históricas se encuentran, también, en Ruiz-Tagle, P., “Apuntes sobre Libertad de Expresión y Censura en Chile”, en Ruiz-Tagle, P., Derecho, Justicia y Libertad: Ensayos de derecho chileno y comparado, Fontamara S.A., México D.F., 2002, pp. 140-2.

9 Altas fuentes de la Iglesia Católica realizaron un intenso lobby para impedir que la banda inglesa Iron Maiden ingresara al país. Acusados de satánicos por la Iglesia, el obispo de Puerto Montt Bernardo Carazzo afirmaba, en 1992, que "a veces lo que se llama arte pisotea la moral”. Ciudad, J., 1992. "La Oleada Demoníaca”, en Revista Rockaxis, No 65 (Marzo), 2008, p. 47

${ }^{10}$ Corte Suprema, Santiago, 17 de junio de 1997, Causa Rol 519-07.

${ }^{11}$ El caso de Alejandra Matus y su "El Libro Negro de la Justicia Chilena", en el marco de un proceso por infracción a las normas de desacato contenidas en el (hoy derogado) artículo 6.b de la Ley de Seguridad del Estado, Decreto Nº 890 Ministerio del Interior (D. Of. 03.07.1975).

12 Como ocurrió con el libro "Cecilia, la vida en Llamas", de Juan Cristóbal Peña, cuya incautación fue ordenada en el marco de un juicio por el delito de injurias. $1^{\text {er. }}$ Juzgado del Crimen de Santiago, 2 de diciembre de 2002, Causa Rol 172.399-3.

${ }^{13}$ La serie 'Epopeya', como se conoce, recreaba situaciones de la Guerra del Pacífico. Universidad Diego Portales, Informe Anual sobre Derechos Humanos 2007, Universidad Diego Portales, Santiago, 2007, pp. 64-5. 
grupo de abogados intente acciones judiciales contra un desfile de modas con diseños inspirados en la iconografía de la Virgen María ${ }^{14}$ o que un juez se querelle en contra de una humorista cuando es aludido en una rutina humorística ${ }^{15}$.

La existencia de avances normativos, de una parte, con fuertes restricciones desde el punto de vista práctico, de otra, puede explicarse, me parece, por tres razones. Primero, en las excepciones legales que abren la puerta a la inevitable tensión en el derecho. En efecto, tal como advirtiera Marx, el derecho es en sí mismo tensión: "[c]ada artículo de la Constitución contiene, en efecto, su propia antítesis, su propia cámara alta y su propia cámara baja. En la frase general la libertad; en el comentario adicional, la anulación de la libertad"16. Lo mismo es predicable respecto del artículo $19 \mathrm{~N}^{\circ} 12$ de la Constitución que asegura a todas las personas la libertad de emitir opinión e informar, sin perjuicio de la profusa regulación (limitaciones, restricciones y responsabilidades) que la misma Carta detalla. Segundo, esas mismas excepciones al derecho pueden llegar a adquirir más fuerza que la propia libertad en la medida que son potenciadas con las concepciones culturales, religiosas y morales de autoridades y, dentro de ellas, de nuestros jueces ${ }^{17}$. Tercero, influye en esta tensión el hecho de que carezcamos de una teoría política, siquiera una discusión seria, en torno a los valores que sirve la libertad de expresión.

El plan es el que sigue. (I) En la primera sección analizaré, brevemente, las concepciones doctrinarias tradicionales que se han esgrimido respecto al reconocimiento constitucional de la libertad de expresión en Chile. Veremos que los profesores de derecho han estado más preocupados de ir definiendo palabra por palabra los atributos de la libertad de expresión, pero especialmente los límites de ésta. En esta misma parte insistiré con que la creación artística se encuentra cubierta por la libertad de expresión. La sección siguiente (II) se encarga de presentar el origen del mito, esto es, la raíz que permite eludir las referencias a la libertad de expresión en el arte para, en cambio, otorgar protección por razones mucho más débiles -y, por lo mismo, más fáciles de revertir. (III) Enseguida avanzaré el análisis de la recepción del mito por parte de nuestras instancias de decisión. Mostraré con el análisis de cuatro casos prácticos cómo es posible proteger las expresiones artísticas sin recurrir a una argumentación en torno a la libertad de expresión. (IV) La cuarta sección la reservo para sugerir algunas ideas - profusamente defendidas

${ }^{14}$ Recurso cuya orden de no innovar fue rechazada (15 de enero de 2009), lo que permitió la realización del desfile. El recurso sería finalmente rechazado. Aceptarlo -sostuvo la Corte de Apelaciones de Santiagoimplicaría incurrir en un acto de censura previa prohibido por la Constitución. Corte de Apelaciones de Santiago, 2 de junio de 2009, Rol Causa 357-2009. Sobre este recurso vuelvo más abajo con algo más de detalle.

${ }^{15}$ Se trata del juez Daniel Calvo quien se querelló por alusiones a su conocida historia en el contexto de denominado "Caso Spiniak". Véase sobre el caso, en general, Universidad Diego Portales, Informe anual sobre Derechos Humanos 2003, Santiago, Universidad Diego Portales, 2003, pp. 261-3.

${ }^{16}$ Marx, K., El 18 Brumario de Luis Bonaparte, Prometeo Libros, Buenos Aires, 2003, pp. 30-1.

${ }^{17}$ En el caso de los Estados Unidos, por ejemplo, la discusión sobre la protección que la primera enmienda otorga a la expresiones obscenas se ha decidido con fuerte influencia de las concepciones ideológicas de los jueces de turno. Sunstein, C. R. et al., Are Judges Political? An Empirical Analysis of the Federal Judiciary, Brookings, Washington D.C., 2006, pp. 93-5. 
en la práctica comparada- en torno a los valores políticos a los que sirve la libertad de expresión, de suerte de poder sugerir a nuestras instancias de decisión no temerle a una defensa vigorosa de la misma. Dejo algunas conclusiones para el final.

\section{LIBERTAD DE EXPRESIÓN Y CREACIÓN ARTÍSTICA}

El artículo $19 \mathrm{~N}^{\circ} 12$ de la Constitución asegura a todas las personas la "libertad de emitir opinión y la de informar, sin censura, en cualquier forma y por cualquier medio, sin perjuicio de responder de los delitos y abusos que se cometan en ejercicio de estas libertades ...". Con la Ley $\mathrm{N}^{\circ} 19.742$ en $2001^{18}$ se incorporó un nuevo inciso al numeral 25 del artículo 19. El precepto ahora se lee de la siguiente forma:

"La Constitución asegura a todas las personas:

"La libertad de crear y difundir las artes, así como el derecho del autor sobre sus creaciones intelectuales y artísticas de cualquier especie ...”.

La discusión que sugiere dicha reforma apunta a si acaso la protección constitucional de la libertad de creación artística existe solo desde la reforma de 2001 o si, en cambio, ella se encontraba ya incorporada a la libertad de expresión. Voy a sugerir esto segundo.

\section{A. Libertad de expresión}

La doctrina nacional casi unánimemente ha insistido, aunque con tratamientos distintos, en que el artículo $19 \mathrm{~N}^{\circ} 12$ reconoce dos libertades: la de opinión y la de información. Ambas -se ha señalado- pueden cobijarse bajo el paraguas de la libertad de expresión, pero apuntan a diferentes objetivos. Cea, por ejemplo, comentando la Constitución de 1980, ha sostenido que la "opinión es un juicio de valor sobre un problema formulado por quien, poseyendo un conocimiento intermedio entre la ignorancia y la ciencia, se pronuncia ante una audiencia sobre sus posibles causas y soluciones ..." ${ }^{\text {19 }}$. Nótese que Cea no está dispuesto a conceder a la opinión absoluta libertad para fluir desde que afirma que, quien opina, lo hace "consciente de que carece del saber suficiente para dictaminar con certeza" 20 . Incluso reafirmando estas definiciones agrega que "opina, en consecuencia, quien no está seguro de lo que expresa..."21.

\footnotetext{
${ }^{18}$ Publicada en el D. Of. 05.08.2001.

${ }^{19}$ Cea, J., Tratado de la Constitución de 1980. Características Generales. Garantías Constitucionales, Editorial Jurídica de Chile, Santiago, 1988, p. 93.

${ }^{20} \mathrm{Id}$.

${ }^{21}$ Cea, J., Derecho Constitucional Chileno, Tomo II: Derechos, Deberes y Garantías, Ediciones Universidad Católica de Chile, Santiago, 2004, p. 370.
} 
La libertad de información, por su parte, consiste en la facultad para acceder a las fuentes de libertad y opinión y de difundir lo que se ha "hallado" 22 . Acá la realidad adquiere una mayor fuerza. Mientras en la opinión Cea estaba dispuesto a tolerar el error del que opina sobre algo que no conoce muy bien, en el caso de la libertad de información la difusión se encuentra supeditada a que exista algo "hallado" que, posteriormente, se entrega al conocimiento de los demás.

A pesar de que más adelante Cea afirma en términos menos estrictos que la opinión se concibe "como la más amplia de las libertades intelectuales, consistente en la facultad que tiene toda persona de exteriorizar, por cualquier medio y sin coacción, lo que piensa o cree" 23 , luego va a sostener que la libertad de información es supuesto de la opinión. El problema que la subyugación de la opinión a la información plantea para la libertad de expresión aflora con Ángela Vivanco -quien sigue de cerca de Cea en este punto. Según Vivanco, que la opinión presuma la libertad de información quiere decir que para opinar se requiere previamente de hechos objetivos ${ }^{24}$. "[P]ara opinar-insiste- hay que tener libre acceso a las informaciones" 25 .

En un esquema tal, libertad de opinión y de información parece relacionarse de forma diferente con la realidad -si es que existe ${ }^{26}$. Lo que el tratamiento de la libertad de opinión parece sugerir es que la realidad no es tan relevante mientras estemos dispuestos, como Cea, a entregarle al emisor el derecho a la ignorancia. En la información no. La libertad de información "incluye[] la narración objetiva de los hechos" por cualquier medio, según sugiere $\mathrm{Cea}^{27}$, donde debe privilegiarse la "mayor objetividad posible", en palabras de Vivanco ${ }^{28}$. Pero desde que la opinión está supeditada, como se afirma, a la información, la aparente latitud que se le concedía a la opinión colapsa en la "mayor objetividad posible" que se reclama para ejercer (legítimamente-constitucionalmente) la libertad de informar.

Verdugo, Pfeffer y Nogueira, en cambio, se acercan más a las teorías que han ganado adhesión en derecho comparado, donde la opinión se considera "una proyección de la autonomía de la persona humana ... que implica el derecho de expresar libremente, y sin autorización previa, opiniones políticas, filosóficas, científicas o religiosas, sea

${ }^{22}$ Cea, Tratado de la Constitución ..., op. cit. p. 97

${ }^{23}$ Id. Evans de la Cuadra también va a sugerir una concepción amplia de opinión que luego, también, sujeta a la libertad de información. Evans de la Cuadra, E., Los Derechos Constitucionales, Tomo II, Editorial Jurídica de Chile, Santiago, 1999, pp. 15-7.

24 “[S]i la opinión es un juicio que ha de emitirse sobre un problema planteado ... debe el individuo conocer tal problema antes de emitir o aun de formar su propio juicio u opinión”. Vivanco, A., Curso de Derecho Constitucional, Tomo II: Aspectos Dogmáticos de la Carta Fundamental de 1980, Ediciones Universidad Católica de Chile, Santiago, 2004, p. 370. También Cea, para quien la información es "el caudal de conocimientos que incluyen tanto la narración objetiva de los hechos ...”. Cea, J., Derecho Constitucional ..., op. cit., p. 357.

${ }^{25} I d$., p. 371.

${ }^{26}$ Una interesante perspectiva sobre el realismo en Putnam, H., Las Mil Caras del Realismo, Editorial Paidós, Barcelona, 1994.

${ }^{27}$ Cea, J., Derecho Constitucional ..., op. cit., p. 357.

${ }^{28}$ Vivanco, A., Curso de Derecho Constitucional ..., op. cit., p. 371. 
por la palabra, sea por la escritura" 29 y sea -como dispone la propia Constitución- por cualquier medio. Como acertadamente -secundándolos- afirma Pedro Anguita, estos juicios personales que se exteriorizan poseen "una dimensión altamente subjetiva [que] no puede quedar sometida a una prueba o test de veracidad" 30 . Como señaló la Corte Suprema de los Estados Unidos en Gertz, bajo "la protección de la primera enmienda no existen las ideas falsas" ${ }^{31}$. Exigir la verdad como estándar de las opiniones llevaría a la libertad de expresión a perder sentido, sobre todo en asuntos sobre los cuales todos queremos manifestar nuestro parecer ${ }^{32}$.

Los mismos autores entienden que la libertad de información faculta a las personas tanto como para difundir información como para reclamar acceso a ella ${ }^{33}$. Vivanco reclamaba la mayor objetividad posible para el ejercicio de esta libertad. Anguita, acertadamente, señala que ese es un reclamo ético (en particular al periodista, central en la difusión de información) que reposa en un estándar mucho más elevado que el jurídico ${ }^{34}$. En efecto, en el derecho comparado la verdad -que es relevante- antes que enarbolarse como piedra de toque del ejercicio de la libertad de expresión cede en sus pretensiones restrictivas ante la razonabilidad de la conducta de quien se expresa. En el caso de los Estados Unidos, la Corte Suprema, por ejemplo, ha señalado que los funcionarios públicos pueden reclamar daños civiles no cuando la información que se divulga es falsa, sino cuando logren acreditar que las informaciones han sido publicadas conociendo su falsedad o, en caso de no conocerla, con absoluta indiferencia respecto a ella ${ }^{35}$.

Veremos, finalmente, que sostener una u otra tesis no es irrelevante para el arte y su relación -siempre difícil- con los hechos y la realidad ${ }^{36}$.

${ }^{29}$ Verdugo, M., Pfeffer, E. y Nogueira, H., Derecho Constitucional, Tomo I, Editorial Jurídica de Chile, Santiago, 1999, p. 260.

${ }^{30}$ Anguita, P., El derecho a la Información en Chile, Editorial LexisNexis, Santiago, 2005, pp. 22-3.

${ }^{31}$ Gertz v. Robert Welch, Inc., 418 U.S. 323 (1974), p. 339.

32 "Aunque se trate de opiniones perniciosas, su corrección no debe depender de la conciencia de los jueces y los jurados, sino de los resultados de su competencia con otras ideas". Gertz, cit., pp. 339-40.

${ }^{3}$ Verdugo, M., Pfeffer, E. y Nogueira, H., Derecho Constitucional, op. cit., p. 261. Esta tesis ha sido también asumida por el Tribunal Constitucional (Santiago, 30 de octubre de 1995, Causa Rol 226 y ratificado con fuerza el 9 de agosto de 2007, Rol Causa 634), y luego por el propio constituyente y la legislación en torno al derecho de acceso a la información.

${ }^{34}$ Anguita, P., El derecho a la información, op. cit., pp. 25-6.

35 El estándar surge en New York Times v. Sullivan, U.S. 376 U.S. 254 (1964). Como bien explica la misma Corte Suprema en Gertz, este mismo estándar fue luego extendido a las "figuras públicas", y de ellas a las "situaciones de preocupación pública". Gertz v. Robert Welch, Inc., 418 U.S. 323 (1974), pp. 334-7. En Alemania el Tribunal Constitucional de ese país ha mantenido un estándar similar. Véase, Schwabe, J. (comp.), Cincuenta Años de Jurisprudencia del Tribunal Constitucional Alemán, Konrad Adenauer Siftung, Montevideo, 2003, p. 137-40.

36 "El artista tiene, en cuanto al conocimiento de la verdad, una moralidad más débil que la del pensador, no quiere en modo alguno dejarse arrebatar las interpretaciones brillantes, profundas de sentido, y se pone en guardia contra métodos y resultados sencillos y serenos". Nietzsche, F., Humano, demasiado bumano, Edaf, Madrid, 1984, p. 134. 


\section{B Libertad de creación artística}

¿Se encuentra la libertad de creación artística contenida en la libertad de expresión? Como señalé antes, una reforma constitucional del 2001 agrega un nuevo inciso al artículo $19 \mathrm{~N}^{\circ} 25$ de la Constitución, asegurando a todas las personas "libertad de crear y difundir las artes”. ¿Es posible afirmar que, gracias a este nuevo inciso, tenemos, y solo desde entonces, la libertad de crear y de difundir creaciones artísticas? ¿ $\mathrm{O}$, en cambio, es correcto afirmar que solo se encarga de detallar un aspecto muy particular de una libertad que se encontraba ya protegida por la libertad de expresión? Creo que solo se detalla una libertad ya protegida (en especial en torno a la propiedad sobre las creaciones), por lo que la primera pregunta debería ser contestada negativamente, mientras la segunda afirmativamente ${ }^{37}$.

Primero una razón sistemática. Si miramos el contexto, el numeral ${ }^{38}$ y las palabras que se utilizan para la incorporación de este nuevo precepto, más que una nueva libertad estamos simplemente en presencia de una especificación de lo que ocurre con la propiedad de las creaciones artísticas, cuestión que se explica, en parte, por la obsesión de nuestro constituyente ('originario' y 'derivado') con el derecho de propiedad ${ }^{39}$.

Segundo, hay razones sustantivas para afirmar que la libertad de creación artística se encontraba ya protegida por la libertad de expresión consagrada en el artículo 19 $\mathrm{N}^{\mathrm{o}} 12$ de la Constitución. Si la creación artística (o mejor dicho, el arte) puede entenderse comprendida dentro de las formas de expresión protegidas por la libertad del artículo $19 \mathrm{~N}^{\circ} 12$, entonces es cierto que la reforma de 2001 solo se encarga de regular

${ }^{37}$ Entre quienes contestaron afirmativamente la primera pregunta, y negativamente la segunda, estaba Vial, T., "La Libertad de Creación Artística. Un nuevo derecho constitucional", en Informe de Investigación $N^{o}$ 19, Centro de Investigaciones Jurídicas, Universidad Diego Portales, Santiago, 2004. Vial abandona esa posición en “El Derecho a la Libertad de Creación Artística en la Constitución”, en González, F. (ed.), Libertad de Expresión en Chile, Universidad Diego Portales, Santiago, 2006.

38 No porque el numeral importe en sí, como sostuvo la Corte de Apelaciones de Santiago -decisión confirmada por la Corte Suprema- al asegurar que el orden numérico que sigue el reconocimiento de derechos fundamentales en la Constitución responde a la mayor o menor jerarquía entre los ellos. Corte de Apelaciones de Santiago, 31 de mayo de 1993, Causa Rol 983-93. Cea ha sostenido, entre los profesores de derecho, la preferencia numérica entre derechos fundamentales. Cea, J., Derecho Constitucional ..., op. cit., pp. 66-7.

${ }^{39}$ Así, por ejemplo, y a propósito del posible aumento de penas para el delito de piratería, los senadores Orpis y Gazmuri señalaron que "hay que ir endureciendo todo lo que son las penalidades porque atenta contra la propiedad intelectual y el derecho de autor y las personas que realizan grandes esfuerzos por desarrollar sus creaciones ... ". "Cambio cultural se percibe como 'indispensable' para combatir la piratería”, en Diario de Noticias del Senado, 27 de agosto de 2004, disponible en: http://www.senado.cl/prontus_senado/antialone. html?page=http://www.senado.cl/prontus_senado/site/artic/20040827/pags/20040827135045.html (visitado el 26 de septiembre de 2007). En este mismo sentido, resulta relevante destacar que la versión original del artículo $19 \mathrm{~N}^{\circ} 25$ se enmarca, igualmente, en las discusiones que la comisión redactora de la Constitución sostenía a propósito del derecho de propiedad. Consúltese, Evans de la Cuadra, E., Los Derechos Constitucionales, Tomo III, Editorial Jurídica de Chile, Santiago, 1999, pp. 428-9 y 433-45. En materia jurisprudencial, por su parte, los reclamos de autores sobre los derechos que pueden cobrar por la difusión de sus obras también se han decidido -a su favor- recurriendo al artículo $19 \mathrm{~N}^{\circ} 25$. Corte de Apelaciones de Santiago, 25 de agosto de 2008, Causa Rol 339. 
la propiedad sobre esas creaciones o, en el mejor de los casos, detalla una "forma particular de ejercer la libertad de expresión” ${ }^{40}$. En el derecho comparado, por ejemplo, se ha entendido que en el contexto de la libertad de expresión éstas, las expresiones, pueden realizarse no solo por medio de palabras y letras, sino que también a través de $\operatorname{actos}^{41}$ y $\operatorname{símbolos}^{42}$. Que el gasto monetario en campañas electorales también es una forma de expresión ${ }^{43}$, y que incluso el silencio posee valor comunicativo ${ }^{44}$. Las artes, desde luego, no quedan fuera ${ }^{45}$.

En Chile nuestra doctrina también ha entendido que las expresiones pueden adoptar las más diversas formas pudiendo ser manifestadas a través de distintos medios: "prensa, libro, folleto, volante, cartel ... por la palabra hablada ... en forma directa o a distancia" ${ }^{4}$.

La protección a las expresiones se gatilla siempre y cuando exista, justamente, una expresión que proteger ${ }^{47}$. Y para ello basta que la conducta "esté lo suficientemente imbuida de elementos comunicacionales que caigan al amparo" de la protección constitucional $^{48}$. Las expresiones que la libertad de expresión protege, entonces, no son solo aquellas que se manifiestan en forma verbal o impresa (métodos tradicionales), sino que todas aquellas que, exteriorizadas de cualquier forma, por ejemplo a través de conductas, intentan comunicar opiniones o entregar mensajes. En el caso de las artes, en particular, y para entender su estrecha vinculación con la libertad de expresión, es preciso tener presente que éstas han jugado un importante papel en los movimientos políticos y so-

${ }^{40}$ Como sostuvo Paulina Urrutia, Ministra del Consejo Nacional de la Cultura y las Artes, Senado, Informe de la Comisión de Constitución, Legislación, Justicia y Reglamento, Boletín No 5.987-04, 28 de julio de 2009, Valparaíso, p. 9.

${ }^{41}$ Como la quema de la bandera de los Estados Unidos, en Texas v. Johnson, 491 U.S. 397.

42 West Virginia State Board of Education v. Barnette, 319 U.S. 624 (1943).

43 Buckley v. Valeo, 424 U.S. 1 (1976).

${ }^{44}$ Wooley v. Maynard, 430 U.S. 705 (1977) ("El derecho a la libertad de pensamiento, protegido por la primera enmienda en contra de la invasión estatal, protege ambos, el derecho a hablar libremente así como el de abstenerse de pronunciar palabra en absoluto").

${ }^{45}$ El caso alemán presenta, quizás, una excepción, desde que el mismo precepto de la ley fundamental $\left(\right.$ art. $5^{\circ}$ ) que consagra la libertad de expresión, reconoce que "[e]l arte y la ciencia ... son libres".

46 Verdugo, M., Pfeffer, E. y Nogueira, H., Derecho Constitucional, op. cit., p. 261; Cea, J., Derecho Constitucional ..., op. cit., p. 359; Evans de la Cuadra, E., Los Derechos Constitucionales, Tomo II, op. cit., p. 16-7.

${ }^{47}$ En el contexto del Sistema Interamericano de protección de derechos humanos, por su parte, se ha entendido que la protección contemplada en la Convención Americana sobre Derechos Humanos incluye no solo a las expresiones orales y escritas (los medios tradicionales), sino que las expresiones que se manifiesten por cualquier medio o procedimiento-como ocurre con las artes. Citando la sentencia de la Corte Interamericana de Derechos Humanos en el caso 'La Última Tentación de Cristo,' decidido en contra del Estado de Chile, recuerda que la norma del artículo 13 de la Convención "establece el derecho a recibir información en forma de arte o en cualquier otra forma ... ". Center for Justice and International Law, Protection of the Right to the Freedom of Expression in the Inter-American System, Cejil, San José, 2006, p. 139.

48 Texas $v$. Johnson (cit.). 
ciales a través de la historia ${ }^{49}$. De hecho, las mayores amenazas a la libertad de creación artística "han estado invariablemente basadas, no el trabajo de los artistas, sino que en sus opiniones políticas y sociales, afiliaciones y actividades reales o presuntas...”. Además de su rol en la política y la cultura, las artes poseen un valor estético en sí mismas que merece protección al amparo de la libertad de expresión, no solo en tanto se trata de expresiones individuales ${ }^{50}$, sino que también por su poderosa dimensión social ${ }^{51}$.

Todo lo anterior no quiere decir ni que todas las conductas reciban necesariamente protección al amparo de la libertad de expresión, ni que solo las expresiones de discurso político sean amparadas constitucionalmente. Esa protección, como he venido señalando, va a depender en gran medida del tipo de regulaciones con las que se encuentre de frente $^{52}$. Si las regulaciones a la conducta, como ocurre por ejemplo con las regulaciones gubernamentales relativas a protestas sociales, buscan eliminar, sofocar o ahogar la expresión, entonces la protección cobra vigor ${ }^{53}$. Quizás por lo mismo conviene -siguiendo a Barendt-centrarse no tanto en las diferencias que existen entre 'discurso' y 'conducta,' sino en cuál es el propósito que persiguen de las regulaciones legales que restringen la comunicación de ideas o información ${ }^{54}$.

${ }^{49}$ Lo que las conecta fuertemente con la protección que recibe el discurso de crítica política. Interesantes e importantes trabajos sobre el papel del arte y el cambio político y social en Chile, en Castillo, E., Puño y Letra: Movimiento Social y Comunicación Gráfica en Chile, Ocho Libros Editores, Santiago, 2006. También Vial, Libertad de Creación Artística, op. cit., pp. 246-7.

${ }^{50}$ Tomás Vial, Libertad de Creación Artística, p. 247 (argumentando que la libertad de creación artística se ha fundamentado en la autonomía humana indispensable para el libre desarrollo de la persona, "en razón de la estrecha conexión que existe entre la persona del artista y su creación").

${ }^{51}$ Goodrich, L., "Freedom of Expression in the Arts I", en Art Journal, No 25, 1965, pp. 44-5 ("Artistic freedom incluyes not only the artist's right to free expression ... it also incluyes the public's right to see and hear what he [or she] produces"). En algún sentido similar se ha argumentado que el autor de una obra, una vez que la crea, da un paso al costado en deferencia al lector quien entonces es liberado para encontrar el placer de ésta. El nacimiento del lector, así, debe considerarse como una consecuencia necesaria de la muerte del autor. Hancher, M., "Dead Letters: Wills and Poems", en Texas Law Review, No 60, 1982, p. 510.

52 Fallon, Jr, R., The Dynamic Constitution. An Introduction to American Constitucional Law, Cambridge University Press, Nueva York, 2004, pp. 42-4 (Analizando el estándar impuesto en United States v. O' Brien, donde la Corte Suprema de los Estados Unidos debía decidir si la criminalización de la quema de tarjetas de reclutamiento militar durante la guerra en Vietnam afectaba la manifestación de ideas -en específico las de aquéllos y aquéllas que se oponían a la guerra).

53 Lo que no ocurrirá cuando la regulación posea justificación distinta a la de la supresión de las expresiones. Eso no quiere decir que el Estado sea libre para intentar justificar sobre la base de cualquier interés sus regulaciones. Aun cuando éstas no busquen directamente ahogar las expresiones, es posible que un efecto indirecto de ellas sea justamente la disminución de la crítica política. En otras palabra, el Estado tiene la pesada carga de demostrar, al menos: (a) que se trata de una medida razonable y que, (b) de todas las medidas disponibles, la escogida es la menos restrictiva para los derechos fundamentales.

${ }^{54}$ Barendt, E., Freedom of Speech, Oxford University Press, Oxford, 2007 (2a ed.), p. 77. Owen Fiss ha llamado la atención sobre posibles estándares de regulación de las expresiones como el arte que, a pesar de aparecer como estándares neutrales -es decir, que no diferencian desde el punto de vista del contenido de las expresiones (como la decencia) - pueden terminar perjudicando sistemáticamente a ciertos puntos de vista, empobreciendo el debate público, de una parte, y marginalizando expresiones provenientes de sectores tradicionalmente excluidos, de otra. Fiss, O., La Ironía de la Libertad de Expresión, Gedisa, Barcelona, 1999, p. 56. Recientemente, además, es interesante notar el giro de la jurisprudencia de los Estados Unidos. Mientras 


\section{El ORIGEN DEL Mito}

En 1988 la Corte Suprema de los Estados Unidos debía pronunciarse sobre la demanda de daños que el reverendo Falwell había presentado en contra de la revista Hustler. La revista había incluido en sus páginas una parodia de un anuncio de Campari ${ }^{55}$ donde el reverendo confesaba -en una entrevista supuesta- que "su primera vez había sido con mamá”, luego de varios camparis. La revista había sido condenada en primera instancia al pago de una indemnización de US\$200.000 por haber ocasionado angustia emocional (daño moral) al reverendo.

La Corte Suprema, en cambio, revocó la decisión. Entre los diversos argumentos que utilizó para desestimar la indemnización de perjuicios solicitada por el reverendo -entre ellos el estándar de la 'real malicia' ${ }^{56}$ - me interesa destacar aquel razonamiento que da nacimiento al mito de la libertad de expresión en la creación artística, en los términos expresados en la introducción de este trabajo. La Corte, argumentando sobre la base de la libertad de expresión, indicó que el aviso era incapaz de provocar daño a la imagen del reverendo Falwell. Además de notar que el mismo aviso contenía una nota al pie en la que señalaba "anuncio parodia: no tomar en serio", afirmó que las figuras públicas que se encuentran íntimamente involucradas en la adopción de importantes decisiones públicas, están más expuestas al discurso crítico ${ }^{57}$.

Esa especial posición de influencia en que se encuentran ciertas figuras públicas las coloca ante la posibilidad de ser objeto de afirmaciones falsas -como ocurría con el anuncio-parodia de la revista demandada. En seguida la Corte argumentó que este tipo de afirmaciones, las falsas, "carecen de valor; interfieren con la búsqueda de la verdad que el mercado de las ideas promueve, y causan un daño a la reputación de las personas que no puede repararse fácilmente con un contradiscurso..." 58 . A pesar de todo ello, "se trata de afirmaciones inevitables" 59 que de ser penalizadas provocarían un silenciamiento de la crítica ${ }^{60}$.

antes la protección que la primera enmienda dependía exclusivamente del tipo de discurso en juego -siendo el discurso político el tipo de expresión que obtiene la mayor tutela- hoy aparece un nuevo actor en escena: el Estado. Las regulaciones que el Estado puede imponer a la entrega de recursos -y un caso corriente ocurre con las artes y los fondos concursables- pueden ser evaluadas con mayor o menor latitud dependiendo del ropaje con que se vista el Estado (sea como empleador, regulador, entre otros). Un análisis en Harvard Law Review $\mathrm{N}^{\circ} 1$ Vol. 123, noviembre 2009, pp. 242 y ss.

55 Una copia de la caricatura la pueden encontrar en la siguiente dirección: http://boingboing.net/ images/falwell-hustler-first-time.jpg (visitada el 28 de enero de 2010).

56 Ver nota 35.

57 Hustler Magazine, Inc. et al. Jerry Falwell, 485 U.S. 46 (1988).

${ }^{58} \mathrm{Id}$.

${ }^{59} \mathrm{Id}$.

${ }^{60}$ Robert Post ha sugerido que la tesis implícita del caso es una que reivindica el carácter no elitista y amplio del discurso público -sobre el que vuelvo hacia el final. Post, R., "The Constitutional Concept of Public Discourse: Outrageous opinion, Democratic Deliberation, and Hustler Magazine v. Falwell”, en Harvard Law Review, No 3, Vol. 103, enero 1990. 
¿Qué ocurre con la falsedad de las expresiones? La Corte se enfrenta al análisis de una parodia. Habría sido ridículo que se intentara reclamar la veracidad de lo afirmado en el mensaje. Lo que resulta importante destacar es el paso que avanza la Corte al decidir como lo hizo: la falsedad de las expresiones no es razón suficiente para privarlas de la protección constitucional que brinda la libertad de expresión ${ }^{61}$. En el contexto de figuras públicas, sostuvo la Corte, las falsedades no solo son inevitables, sino muchas veces deseables en tanto gatillan una crítica política de la cual, quienes influyen en la adopción de decisiones públicas, no deben escapar ${ }^{62}$. Algo similar había señalado la Corte en Gertz, al afirmar que "aun cuando las informaciones falsas no merecen protección constitucional, son inevitables en un debate libre ..." Permitir que las figuras públicas puedan demandar daños si es del caso que el demandado no logra probar la verdad, "implica no solo que se impedirán las informaciones falsas", sino que provocará que la comunidad toda omita expresarse por miedo, justamente, a no poder probar la verdad de sus afirmaciones ${ }^{63}$.

Esto, en el contexto del arte, es muy relevante. Nótese cómo la Corte define a las caricaturas como "figuras o imitaciones deliberadamente distorsionadas de personas ... donde se exageran ciertas maneras o rasgos con intención de producir efectos satíricos" 64 . Y volvamos con Nietzsche: "El artista tiene, en cuanto al conocimiento de la verdad, una moralidad más débil que la del pensador ... En apariencia, lucha por la dignidad y la importancia superior del hombre; en realidad, no quiere abandonar las condiciones más eficaces para su arte, tales como lo fantástico, lo mítico, lo incierto, lo extremado, el sentido del símbolo, la sobrestimación de la personalidad, la creencia de que hay algo milagroso en el genio ..." ${ }^{65}$. Por supuesto que hay creaciones artísticas -y la sátira lo es de alguna forma- que arrancan de la realidad. Pero justamente la fuerza del arte radica en que el artista no es un difusor de informaciones. Es, como lo sugiere el filósofo alemán, alguien que confía en su genio creador para extremar los hechos planos. Esto es lo que la Corte Suprema de Chile no logró advertir cuando censuró 'La Última Tentación de Cristo' al afirmar como hechos objetivos que "Jesucristo, históricamente, vivió hace dos mil años y murió crucificado ..." 66 . Y es, en cambio, lo que sí advierte brillantemente la Corte de Apelaciones de Santiago en el caso del libro 'Difícil Envoltorio'. En dicho

${ }^{61}$ En Chile hemos conocido de casos en que nuestros tribunales han privado de efectos a la libertad de expresión justamente porque el emisor no ha logrado probar la veracidad de sus afirmaciones. Tal fue el estándar que utilizó el Juzgado de Garantía de Puerto Montt para condenar por injurias al abogado Carlos Barahona, en razón de la crítica que dirigió al entonces senador Páez. Una crítica a la forma en que se decidió este caso, y otros, en Lovera, D., "El Interés Público como Estándar. Libertad de Expresión y Vida Privada", en González, F. (ed.), Libertad de Expresión, op. cit., pp. 84-5.

62 Sobre esto vuelvo luego al analizar los casos chilenos: las creaciones artísticas son protegidas sobre la base de una débil defensa de la libertad de expresión (en Chile), o preocupándose demasiado por las parodias, afirmaciones y sátiras falsas (Estados Unidos).

63 Gertz, p. 340.

${ }^{64}$ Hustler Magazine.

65 Nietzsche, op. cit.

${ }^{66}$ Corte Suprema, Santiago, 17 de junio de 1997, Causa Rol 519-97 (el destacado es mío). 
caso la Corte debía pronunciarse sobre recurso de protección presentado por una persona víctima de la dictadura. El libro comienza de hechos reales para luego ceder paso a la imaginación de su autora -afirma- "en que se narra una acción fingida en todo o en parte y cuyo fin es causar placer estético a los lectores por medio de la descripción o pintura de sucesos o lances interesantes ..." ${ }^{67}$. La Corte estima que "no le resulta posible al lector discernir entre hechos reales y ficticios, puesto que si bien la historia de los personajes que contiene se basa en acontecimientos efectivamente ocurridos, es la imaginación de la escritora la que prevalece en el desarrollo de su argumento"68.

¿Qué hay del mito en Hustler? Una cosa es sugerir que una parodia -o el arte- puede arrancar su inspiración de hechos reales para luego trascender a lo divino por obra y gracia del artista y que esas expresiones merecen protección constitucional. Otra cosa, distinta, es afirmar que el arte es incapaz de tomarse en serio y que por lo mismo no se le censura. La Corte Suprema de los Estados Unidos recalca -como luego, veremos, remarcan nuestras instancias - que el uso de la parodia y de la caricatura política es una forma de discurso protegido por la libertad de expresión y que, si bien es cierto que acá (en el caso de la parodia de Falwell) estamos en presencia de una caricatura que vendría a ser -en palabras de la Corte- un "primo lejano" de las caricaturas que han influido en la vida política de las comunidades, merece protección. El mito nace no solo porque esta caricatura -como podría ocurrir con el arte- es desmerecida en comparación a otras expresiones protegidas, sino que particularmente porque la Corte termina su opinión haciendo eco de algunos de los argumentos sostenidos por las cortes de instancia que resolvieron este caso a favor del reverendo: "que la parodia no podría entenderse como una descripción de hechos reales en los cuales el reverendo haya tomado parte ... y fieles a nuestra costumbre concordamos con esta interpretación" 69 .

\section{El Capitán de fragata, Enigma, el Vaticano y la Virgen María}

Nuestras instancias decisorias han también lidiado con casos sobre creación artística. A diferencia de lo que hizo la Corte Suprema de los Estados Unidos en Hustler Magazine, acá nuestras instancias han sostenido que, justamente porque las expresiones que las artes han manifestado no son creíblemente una descripción de hechos reales, no hace falta proteger la honra de los involucrados. Digamos que nuestras instancias decisoras han protegido las expresiones no porque han defendido el valor de la libertad de expresión, sino que porque no han entregado valor alguno a estas formas de expresión. En otras palabras, mientras la Corte norteamericana ataca las expresiones falsas pero enaltece el valor de la libertad de expresión en una sociedad democrática, nuestras instancias atacan las expresiones (de arte) falsas y no se refieren a la libertad de expresión. Y porque se

\footnotetext{
${ }^{67}$ Corte de Apelaciones de Santiago, 31 de octubre de 2000 (el destacado es mío).

${ }^{68}$ Hustler Magazine.

${ }^{69} \mathrm{Id}$.
} 
trata de expresiones falsas -razonan- no pueden afectar el honor de los involucrados. Como veremos en seguida, nuestras instancias decisorias no solo conceden escaso valor a la libertad de expresión, sino que incluso se dan maña de hacer crítica artística -como ocurrió en Prat.

A. En Prat, la Corte de Apelaciones de Santiago debía decidir un recurso de protección interpuesto por familiares del Capitán de fragata, pues entendían que la obra de teatro preparada y montada con ayuda de recursos estatales denostaba la figura del héroe patrio. La Corte de Apelaciones rechazó el recurso sobre la base de una vigorosa defensa de la libertad de expresión, incluyendo en sus argumentaciones estándares del derecho internacional de los derechos humanos. Así, sostuvo que "está fuera de toda discusión que lo que se pretende mediante la presente acción es, precisamente, censurar la pieza teatral denominada Prat por contener referencias que se estiman contrarias a la honra y dignidad del héroe Arturo Prat, de su familia y en general de los chilenos. De aceptarse tal planteamiento mediante la sentencia que se pronuncie respecto a esa acción, se estaría limitando la libertad de expresión y se estaría contraviniendo el artículo 13 de la Convención Americana de Derechos Humanos que, como se señaló, prohíbe toda censura ... la libertad de expresión otorga fundamental importancia a la necesidad de expresar y recibir cualquier tipo de información, pensamiento, opiniones o ideas y dispone categóricamente que las responsabilidades posteriores que puedan producirse deben ser resueltas mediante la decisión de tribunal competente"70.

La Corte Suprema confirmó la decisión eliminando todos los considerandos referidos al derecho internacional y además, para lo que me interesa resaltar acá, haciendo curiosas afirmaciones sobre la obra en cuestión ${ }^{71}$. En línea con las declaraciones finales de la Corte norteamericana en Hustler, acá la Corte Suprema de Chile señaló que:

"en la obra teatral de que se trata, si bien es cierto toma el apellido de una persona constituida en héroe nacional, el protagonista que en ella figura resulta en definitiva tan desfigurado, ubicado en un contexto tan ajeno al de la epopeya naval, y rodeado de personajes tan diferentes de los reales compañeros de su gesta, que no es posible identificarlo a él con personas determinadas, ni tan siquiera aquella con quien los recurrentes relacionan, y menos confundir los acontecimientos allí narrados con los actos heroicos que realizara el Capitán Prat" ${ }^{\text {"2. }}$

${ }^{70}$ Corte de Apelaciones de Santiago, 16 de abril de 2003, Causa Rol 5681-2002.

71 Argumentó, por ejemplo, que "no cabe duda de que el derecho al honor es un atributo de la personalidad de la mayor importancia y de carácter especialísimo, por lo que debe gozar de preeminencia sobre otros derechos ...". Considerando $8^{\circ}$, Rol N 1961-2003, Corte Suprema. Revisiones críticas de esta sentencia en Anguita, P., El derecho a la Información, op. cit., pp. 124-5, y Contesse, J., "Responsabilidad por la Interpretación Constitucional", en Revista Derecho y Humanidades, N ${ }^{\circ} 11,2005$, p. 281. Sobre el uso del criterio de especialidad resolviendo casos en que la libertad de expresión se encuentra involucrada, Lovera, D. Interés Público, op. cit., pp. 86-7.

${ }^{72} \mathrm{Id}$., considerando $10^{\circ}$. 
En otras palabras - de la misma Corte, en todo caso-, la obra en cuestión "corresponde [a] ... una ficción atemporal o un desvarío lúdico, y tal como está presentada, no puede llegar a afectar el honor del héroe nacional ni de los familiares de Arturo Prat Chacón" 73 . No existe en el fallo de mayoría argumento alguno relativo a la importancia de la libertad de expresión, sino solo referencias a la incapacidad de la obra para provocar daño al honor del Prat. Así, mientras el voto de minoría que estaba por censurar la obra no presta atención alguna a la libertad de expresión, el voto de mayoría -que permite su montaje- solo exhibe un total menosprecio por aquélla. Lo que es más preocupante, como lo ha señalado acertadamente Rodrigo Correa, es que si la Corte hubiera estimado que la obra era "artísticamente meritoria y su protagonista hubiera constituido una representación plausible del héroe, el recurso [que buscaba la censura de la obra] habría prosperado" 74 .

B. En Enigma, un grupo de familiares de un abogado asesinado en una fiesta buscaba impedir la emisión de un programa en el que se recreaba el escenario de la muerte. Los recurrentes argumentaban que el programa afectaba el derecho al honor de la familia del abogado, en circunstancias que ellos jamás habían consentido en la recreación y ésta, sostenían, causaba un daño y descrédito a la familia. La Corte de Apelaciones rechazó el recurso. Una de las cuestiones importantes en esta sentencia es que la Corte señala que el conflicto no se limita al análisis del derecho a la honra -invocado por parte de los recurrentes- y la libertad de expresión -por los recurridos. Además, sostuvo la Corte, debía analizarse también el derecho del autor sobre sus creaciones artísticas e intelectuales ${ }^{75}$. De hecho, sostuvo que la libertad de expresión no se consideraría al resolver el recurso, pues se trata de:

"una expresión genérica y, en consecuencia, demasiado amplia, que incluye distintos derechos específicos, como aquellos ya referidos a emitir opinión, a informar y a la creación intelectual y artística, pero que también puede aplicarse a la inviolabilidad de la correspondencia, a la manifestación de todas las creencias religiosas y al ejercicio libre de todos los cultos, a la libertad de enseñanza, e incluso, a los derechos de reunión y de petición"76.

${ }^{73} I d$., considerando $12^{\circ}$. La Corte, además, criticó el financiamiento público de la obra en los siguientes términos: "debe agregarse que la incoherencia de la trama, lo ininteligible de los parlamentos y lo ramplón del tratamiento del tema en general, convierten a la pieza teatral en algo intrascendente y de escasa proyección en el plano de difusión, siendo inexplicable su financiamiento con fondos públicos" (considerando $11^{\circ}$ ).

${ }^{74}$ Correa, R., "Derechos Constitucionales", en Revista de Derecho Universidad Adolfo Ibáñez, N ${ }^{\circ} 1$, 2004, pp. 586-7.

75 Corte de Apelaciones de Santiago, 30 de septiembre de 2003, Causa Rol 4743-2003, Considerando $3^{\circ}$.

${ }^{76} I d$. 
No solo es importante destacar que la Corte considerara a la libertad de creación artística como una manifestación (más específica) de la libertad de expresión ${ }^{77}$, sino la forma en que la Corte considera que la creación artística precede -en este caso concretoal derecho a la honra invocado por los recurrentes. La Corte principia el análisis de la libertad de expresión con un dudoso estándar en que la vincula (tanto en su faz de libertad de información como de opinión) con la verdad. Así, sostiene "[q]ue los derechos a emitir opinión y a informar, especialmente el segundo, contenidos ambos en el art. $19 \mathrm{~N}^{\circ} 12 \mathrm{de}$ la Constitución, también están en íntima relación con el concepto de verdad. En efecto, se informan los hechos realmente ocurridos, los dichos reales de una persona, para que quien no los presenció o escuchó tenga conocimiento de los mismos, quede informado. No se informan falsedades o mentiras: decirlas es precisamente desinformar" ${ }^{\text {" }}$.

El problema con este argumento de la Corte no es solo el que estreche el alcance de la libertad de expresión al vincularla con la verdad - sin reparar en los estándares de diligencia que deben exigirse antes que en fidelidad absoluta a una verdad a veces inalcanzable-, sino el hecho de que la Corte parece contradecirse en sus propios términos. En efecto, la Corte va a sostener que las creaciones artísticas "no están ligadas al concepto de verdad. En ellas, la imaginación y la irrealidad son admitidas libremente. Por estas razones, tales creaciones del espíritu no se informan: simplemente se difunden, en el entendido que no tienen por qué reflejar realidad alguna"79. Como el objetivo del programa no es el de difundir verdades, esto le va a permitir a la Corte cobijar el reclamo de los recurridos bajo la libertad de creación artística. ¿Pero es esto así?

La Corte señaló que "la violación del derecho al honor ... exige que se impute a una persona una falsedad que desvirtúe algún rasgo de su personalidad que ella desea conservar o resaltar". ¿Cómo va a intentar cotejar esto la Corte? "[C]ompara[ndo] la verdad que emana del respectivo expediente criminal, con la cinta de video acompañada ... que contiene copia del programa Enigma elaborado por los recurridos. De esta manera, la Corte pudo comprobar que esa cinta reproduce fielmente dicha verdad procesal" 80 . Esta argumentación es confusa. Si el programa se entiende como manifestación de la libertad de creación artística la Corte debiera haber asumido que éste era incapaz de afectar el honor de los recurridos, toda vez que esta libertad no difunde verdades, sino que solo "imaginación" e "irrealidad". Si la libertad de creación artística no se encarga de difundir verdades, ¿por qué la Corte se preocuparía de cotejar la recreación televisiva con el expediente judicial sobre los hechos? Una respuesta posible es la de entender que

${ }^{77}$ Lo que, dicho sea de paso, no nos permite comprender por qué la Corte “[n]o considerará, en cambio, la libertad de expresión (y su correlato, la libertad de difusión), por estimarla una expresión genérica ...". Si la libertad de expresión es demasiado genérica, en el sentido de que contempla la libertad de creación artística, entonces ella de todas formas debería ser considerada al momento de resolver, máxime cuando la Corte se refiere al derecho del autor sobre sus creaciones artísticas antes que a su libertad para crearlas y difundirlas. $I d$.

${ }^{78} I d$., considerando $5^{\circ}$.

${ }^{79} \mathrm{Id}$.

${ }^{80} I d$., considerando $7^{\circ}$. 
la Corte, al señalar que el expediente presenta una "verdad procesal" (comillas de la Corte), es una suerte de creación artística. Otra, más probable, es la de comprender que la Corte, al distinguir entre libertad de expresión (verdad) y creación artística (irrealidades e imaginación), simplemente terminó confundiéndose. Y ello porque la Corte rechazó el recurso porque el programa, al ser copia del expediente judicial, era incapaz de lesionar el honor de la familia del abogado involucrado. Pero este es un argumento -había dicho la Corte- para proteger la libertad de expresión, sin que fuera necesario gatillar la defensa de la libre creación artística ${ }^{81}$.

¿Qué es lo que me interesa destacar del argumento de la Corte? Si prestamos atención a la forma en que ésta concibe la creación artística veremos, por supuesto, que se avanza un tesis muy restringida de la libertad de expresión, al tiempo que la creación artística es prácticamente irrelevante. Cuando la Corte señala que ésta no informa, sino que solo presenta "irrealidades" e "imaginaciones", busca desplazar el rol de la creación artística a un rol secundario, irrelevante, casi un fetiche, que si recibe protección de las cortes la recibe únicamente -como razonaron las cortes antes- porque el arte, esa creación del artista, es capaz de mostrar algo más que solo una "irrealidad" o "imaginación" 82 .

C. En Papavilla, el Consejo Nacional de Televisión (CNTV) debía pronunciarse sobre un requerimiento presentado por un grupo de particulares en contra de la empresa de cable VTR Global Com S.A., por la difusión del programa 'Papavilla' ${ }^{\text {'3 }}$. El programa de caricaturas animadas muestra la vida del Padre Nicolás en 'Papavilla', en abierta sátira al Vaticano y la Iglesia. Allí se narra no solo la historia del Padre Nicolás, sino la de muchos otros sacerdotes en historias mezcladas con depravación sexual, corrupción y violencia. La serie presenta al Papa como un ser caprichoso y malcriado. Ello llevó a un grupo de particulares a pedir la prohibición de emisión del programa, pues -en su concepto- se trataba de una serie que muestra al Sumo Pontífice y de la Iglesia Católica romana como una figura maligna, con "prácticas reñidas con los derechos humanos [y con] figuras religiosas ... consagradas como prototipos de hipocresía o estupidez”. Todo ello, insistían los requirentes, afectaba "los valores morales y culturales de la Nación, [la] dignidad de las personas, [la] formación espiritual e intelectual de la niñez y de la juventud, [la] libertad religiosa de quienes profesan el catolicismo [y su] derecho a no ser discriminados en razón de su credo religioso" ${ }^{4}$.

${ }^{81}$ La fuerza de la libertad de creación artística entendida como una manifestación de la libertad de expresión radica en que, incluso si el programa no hubiera sido copia fiel del expediente, la Corte debió haber rechazado el recurso.

82 Aunque la Corte, extrañamente, termina comparando el programa con la "verdad procesal" del expediente.

83 www.popetown.com.

${ }^{84}$ Acta de la Sesión Ordinaria del Consejo Nacional de Televisión, 11 de junio de 2007 (disponible en: http://www.cntv.cl/link.cgi/Actas/1170) pp. 18-9. El argumento es tremendamente similar al utilizado por los recurrentes que solicitaron la censura de "La Última Tentación de Cristo". El concepto de los recurrentes, su libertad religiosa se afecta cada vez que alguien cuestiona sus creencias. En rigor, como ha sugerido Alejandra Zúñiga, la libertad religiosa, como una especie del derecho a la libre formación del pensamiento, se 
El requerimiento de sanción sería finalmente rechazado. Sin embargo, el CNTV funda su decisión en una serie de razonamientos que conviene revisar acá por dos motivos. Primero, porque se mantiene en línea con las curiosas afirmaciones que nuestras instancias de decisión han realizado en casos sobre libertad de creación artística. En Prat, la Corte Suprema anunció la precedencia incondicionada del derecho al honor por sobre todos los demás derechos fundamentales ${ }^{85}$. En Enigma, la Corte de Apelaciones justificó la diferencia entre libertad de expresión y libertad de creación artística según la vinculación que tienen una y otra con la "difusión de verdades".

En Papavilla, el CNTV no se quedó atrás y avanzó algunas ideas relativas al rol de la Iglesia Católica en las bases fundacionales de la moral y cultura chilenas. El CNTV señaló que "la Iglesia ha influido substantivamente en la formación de los valores culturales y morales de la Nación chilena ..." 86 . La pregunta que surge inmediatamente es si acaso este tipo de declaraciones deben incorporarse en este tipo de decisiones, sobre todo si el CNTV debe analizar - no solo en este caso, sino que constantemente- reclamaciones en las que se alega la vulneración de "los valores morales y culturales propios de la Nación". Para decirlo con otras palabras, ese reconocimiento que hace el CNTV -sin que sea el mejor situado para realizarlo- entrega a los "valores morales y culturales" de Chile un contenido mínimo. El contenido de esos valores que habilitan al CNTV a ordenar, por ejemplo, sanciones en contra de programas que los vulneren, puede ser amplio, diverso, es cierto. Y el propio CNTV lo reconoce al señalar que, así como la Iglesia ha influido los valores morales y culturales chilenos, no es menos cierto que ella "es también tributaria de los principios que informan la civilización occidental ... entre los cuales ocupan

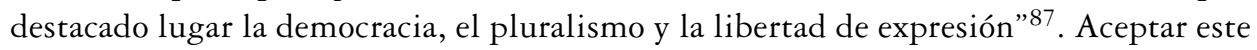
contenido mínimo abre el paso a peligrosas decisiones como la censura de programas que se consideren contrarios a aquél ${ }^{88}$. Y Chile en esto tiene experiencia.

afecta cuando se limitan las posibilidades de acceder libremente a distintas formas de pensamiento. Zúñiga, A., "La libre formación del pensamiento en el caso 'La Última Tentación de Cristo”, en González, F. (ed.), Libertad de Expresión en Chile, op. cit., pp. 291-305.

${ }^{85}$ Robert Alexy, entre otros, ha argumentado que la decisión de conflictos de derechos fundamentales debe realizarse por medio de un juicio de precedencia condicionada. Las condiciones jurídicas y fácticas del caso concreto son, en su tesis, las circunstancias que van a determinar cuál de los principios -esos mandatos de optimización que pueden realizarse en mayor o menor medida- recibirá aplicación preferente (en ese caso concreto). Esta forma de acercarse a los conflictos entre derechos fundamentales, utilizada, entre otros, por los tribunales constitucionales de Alemania y España, proscribe la posibilidad de establecer preferencias incondicionadas, esto es, aplicaciones preferentes en abstracto entre los diferentes derechos. Alexy, R., Teoría de los Derechos Fundamentales, Centro de Estudios Constitucionales, Madrid, 2002, p. 89. Jorge Contesse ha trabajado, sobre la base de este esquema, críticas a decisiones de nuestros tribunales en casos en que se encuentra involucrada la libertad de expresión, en Contesse, J., "Reglas y Principios en Chile: ¿Jerarquía entre los Derechos Constitucionales?”, en Anuario de Filosofía Jurídica y Social, No 20, 2002, pp. 82-91.

${ }^{86}$ Acta de la Sesión Ordinaria del Consejo Nacional de Televisión (cit.), considerando $11^{\circ}$.

${ }^{87} \mathrm{Id}$.

${ }^{88}$ En efecto, los consejeros Chadwick y Brahm fueron de la opinión de formular cargos en contra de los denunciados, argumentando que "el programa es una ridiculización de la Iglesia Católica, cuyos principios forman parte importante de los valores morales y culturales de la Nación...”. 
El segundo motivo por el cual me interesa revisar esta decisión es la razón que convoca este trabajo, esto es, indagar en las razones por las cuales en este caso el CNTV protege la serie en cuestión. A diferencia de lo que ocurrió en Prat y en Enigma, acá el CNTV sí avanza un par de buenas ideas en torno a la libertad de expresión ${ }^{89}$. Argumentó que la libertad de expresión es uno de los pilares sobre los cuales se edifican las democracias plurales $^{90} \mathrm{y}$, en un paso relevante para el contexto nacional, que la Iglesia, en tanto "actor importante en la política internacional y también en los países donde ella tiene influencia", como es el caso de Chile, "es como toda otra institución pública, susceptible de crítica realizada mediante el libre ejercicio de la libertad de expresión ...."91.

Hasta acá el CNTV avanza una defensa de la libertad de expresión. Sin dar la espalda a la realidad, y mucho menos a la realidad de países como Chile, califica a la Iglesia como uno más de los actores relevantes en la definición de las políticas nacionales -e internacionales. Además, en tanto actor público, la somete a la crítica ciudadana. Acá hay buenas razones para entender que la Iglesia queda sometida al control popular de su rol político mediante las expresiones.

Es cierto, entonces, que el CNTV avanza una protección de la creación artística desde la libertad de expresión. Sin embargo, al igual que la Corte Suprema en Prat y que la Corte de Apelaciones en Enigma, no resiste la tentación de minimizar el arte -en este caso, el programa en cuestión- para mirarlo con las gafas de la indiferencia. El mito, esa tesis que sostiene la inocuidad del arte para expresar una opinión sobre la realidad que contrita a la formación del discurso público, vuelve a aparecer. Así, el CNTV señala que, una vez analizados los episodios de la serie, que "ésta puede ser caracterizada como una serie animada de humor, que satiriza por la vía de exponer situaciones, personajes y expresiones absurdas, claramente contrarias a los estereotipos por ellas aludidos, todo lo cual hace de ella una ficción"92.

El mito, acá, nos dice que el arte es irrelevante en la formación de la opinión pública. Por supuesto no hay razones para criticar el hecho de que el CNTV califique la serie como una ficción -a fin de cuentas se trata de caricaturas animadas. Pero sí las hay para analizar esa objetividad que todas nuestras instancias de decisión logran, o creen lograr, apreciar para minimizar el discurso artístico. En Prat, 'lo objetivo' era la gallardía y nobleza a toda prueba del Capitán de Fragata; una mala obra, pensó la Corte, no mancilla la grandeza del héroe nacional. Ahora, 'lo objetivo' es el comportamiento de los miembros de la Iglesia. Por eso es que las situaciones que muestra la serie, cotejadas con 'lo

${ }^{89}$ A no engañarse de todas formas: el caso fue resuelto rechazando la formulación de cargos luego que cuatro consejeros estuvieran por absolver y cuatro por formular cargos -en circunstancias que la ley que crea el CNTV requiere mayoría absoluta de sus miembros.

${ }^{90}$ Acta de la Sesión Ordinaria del Consejo Nacional de Televisión (cit.), considerando $13^{\circ}$.

${ }^{91} \mathrm{Id}$.

${ }^{92} I d$., considerando $8^{\circ}$. 
objetivo,' son -como dice el CNTV_ "expresiones absurdas, claramente contrarias a los estereotipos y convenciones por ellas aludidos..."93. El Consejo insiste con el mito:

"Que, en la serie objeto del reparo, la sátira no parece dirigida a artículos de fe de la religión católica, sino a ciertos aspectos temporales de la Iglesia Católica como institución; así ella se centra principalmente en aspectos vinculados a manejos económicos y financieros; y si bien ella alude a figuras reconocibles dentro de la organización eclesiástica [de hecho, al Papa], éstas están tratadas como símbolos y no como figuras reales a las cuales pudiera la sátira afectar en su dignidad"94.

El CNTV pierde de vista el hecho de que ese modelo 'objetivo' con el que compara la serie es, justamente, un mundo que él no debe dar por sentado, sino uno que se configura justamente con las diferentes informaciones y opiniones a su respecto, entre las cuales debe considerarse el arte. Si bien el CNTV concluye señalando que la irreverencia de la serie no es razón suficiente para privarla de la protección que le garantiza la libertad de expresión ${ }^{95}$, ello no eclipsa la forma en que se acerca al programa declarando, de antemano, que es incapaz de hacer pensar a alguien que se trata de una opinión a ser tomada en cuenta. El mito manda no censurar, pero no porque la libertad de expresión así lo ordene, sino que simplemente porque la creación artística, esa expresión del intelecto del creador, es incapaz de confundirnos y hacernos dudar de 'lo objetivo'.

D. En Vírgenes Fashion Show, finalmente, vuelve a reiterarse la tesis del mito, esta vez con toda su fuerza. Vírgenes Fashion Show era un desfile de modas organizado por el diseñador Ricardo Oyarzún, en el que se presentaban una serie de modelos vistiendo prendas inspiradas en la iconografía de la Virgen María ${ }^{96}$. Los recurrentes, un grupo de abogados, solicitaron la censura de la obra argumentando la violación de su libertad religiosa. Argumentaron que dicha libertad se compone de una faz positiva, que les permite profesar su culto, y una negativa que -sostuvieron- "supone un límite para el resto de las personas, de respetar tal derecho" ${ }^{97}$. Es decir, tolerancia acá, sería equivalente a no criticar.

La Corte de Apelaciones de Santiago va a rechazar el recurso por tres razones ${ }^{98}$. Primero, porque al haberse rechazado la orden de no innovar ya carecía de sentido el

${ }^{93}$ Cuando la verdad es que de tanto en tanto (y no tanto tampoco) los miembros de la Iglesia nos dan muestras justamente de comportamientos -para seguir con el lenguaje del CNTV - "absurdos", "claramente contrarios a los estereotipos y convenciones".

${ }^{4}$ Acta de la Sesión Ordinaria del Consejo Nacional de Televisión (cit.), considerando $10^{\circ}$.

${ }^{95} \mathrm{Id}$., considerando $17^{\circ}$.

96 “Abogados buscan frenar desfile de provocativas 'vírgenes”, La Segunda, 13 de enero de 2009, p. 5.

${ }^{97}$ El recurso se encuentra disponible en: http://www.asociacionderechocanonico.cl/pags/documentos/ docs/boletin_juridico_enero_2009.pdf (visitado el 28 de enero de 2010).

${ }^{98}$ Corte de Apelaciones de Santiago, 2 de junio de 2009, Rol Causa 357-2009 (cit.). 
recurso 99 . Segundo, porque de hacerlo se incurriría en una censura previa prohibida por la Constitución -quedando habilitada la vía para que los recurrentes busquen la reparación de los daños ex post facto ${ }^{100}$. Y tercero, y más importante en el sentido de este trabajo, porque los realizadores están ejerciendo su "libertad de creación artística, que si bien está expresamente reconocida en el numeral 25 del artículo 19 de la Carta Fundamental, constituye sin duda una manifestación de la libertad de expresión que queda amparada por la prohibición de censura previa establecida en el citado $\mathrm{N}^{\circ} 12$ del mismo artículo"101.

La Corte podría haber concluido su análisis acá, lo que cerraría el círculo brindándonos una sentencia ejemplar. La libertad de creación artística, una especie de libertad de expresión, no puede censurarse preventivamente. Pero la Corte, al igual que las instancias anteriores, no pudo resistirse a la fuerza del mito, barriendo, de paso, con la justificación que tan brillantemente había construido en torno a la libertad de expresión. Así, va a firmar que, pese a todo lo anterior, "no se advierte que las impropias e inconvenientes imágenes que conforman la obra del recurrido puedan afectar la libertad de conciencia de los recurrentes ni parece que esta representación tenga la importancia y aptitud suficiente para influir en las convicciones religiosas de los ciudadanos" ${ }^{102}$.

Al igual que en Prat, la Corte no resiste realizar su comentario artístico, mientras que, de paso, y al igual que la decisión en Papavilla, se encarga de minimizar la relevancia expresiva del discurso artístico, como uno que no contribuye a la formación de la opinión pública.

\section{LIBERTAD DE EXPRESIÓN PARA QUÉ}

¿Por qué es relevante criticar los argumentos que nuestras instancias decisorias han esgrimido para no censurar las creaciones artísticas? La razón, sostengo, radica en la escasa fuerza de sus argumentos y, sobre todo, por negar al discurso artístico su capacidad para contribuir a la formación del discurso público. Mientras he explorado la primera de las razones por vía de ilustrar los argumentos de nuestras instancias en los casos previamente reseñados, me vuelco a la segunda crítica, esto es, a la consecuencia necesaria que se siga al negar valor expresivo al arte: el debilitamiento del discurso público.

Entre nosotros debemos a Carlos Santiago Nino la preocupación por notar que la libertad de expresión posee una doble faz, una individual, que permite las expresiones del alma, y una colectiva, que nos permite tomar parte en la configuración de la voluntad popular. Mientras la primera faz de la libertad de expresión se centra en el individuo, la

\footnotetext{
${ }^{99} I d$., considerando $4^{\circ}$.

${ }^{100} I d$., considerando $5^{\circ}$.

${ }^{101} I d$., considerando $6^{\circ}$.

${ }^{102} I d$., considerando $7^{\circ}$.
} 
segunda lo hace en el valor que la libertad posee para el autogobierno ${ }^{103}$. Ambas esferas, en conjunto, pueden comprenderse a la luz del valor que la libertad de expresión posee en sí misma ${ }^{104}$. Tratarlas por separado, considerando únicamente su faz individual -como un derecho que protege solo intereses personales-, en cambio, supone un tratamiento instrumental de la libertad de expresión. En efecto, cuando la libertad de expresión se concibe en términos meramente instrumentales, entonces se la protege únicamente a efectos de permitir los beneficios que se derivarían de ella. La libertad de expresión, acá, no posee valor intrínseco. En los Estados Unidos esta versión de la libertad de expresión ha permitido una fuerte defensa del discurso político ${ }^{105}$, pero ha sido insuficiente frente a otras formas de expresión ${ }^{106}$. El punto, por supuesto, no es que el discurso político no merezca protección. Al contrario, prácticamente todos los argumentos en torno a la libertad de expresión han insistido que su fuerza es particularmente fuerte en casos de discursos político ${ }^{107}$. Lo que la tesis del discurso público sí sugiere es que, además del discurso político, otras formas de expresión también gatillan la protección de la libertad de expresión.

Para ello es preciso entender que la libertad de expresión posee un valor en sí misma. Esto quiere decir -siguiendo a Dworkin-que la libertad de expresión posee un valor inherente que grafica el trato que la comunidad entrega a sus miembros. Cuando la libertad de expresión es entendida de esta forma, la comunidad está tratando a sus miembros como agentes morales plenos y responsables capaces de adoptar sus decisiones, su plan de vida y de intervenir en la definición de los asuntos públicos. Esa condición se respeta cuando se permiten las expresiones políticas y de otro tipo, pero se insulta -negando esa capacidad moral- "cuando el Estado decreta que las personas o están

103 Para Nino, en efecto, los derechos constitucionales -y entre ellos la libertad de expresión- son presupuestos de la práctica social del discurso moral. Se derivan de la autonomía e igual dignidad de las personas, y nos habilitan para ingresar al espacio dentro del cual se adoptan las decisiones colectivas. Nino, C. S., La Constitución de la Democracia Deliberativa, Gedisa, Barcelona, 1997, pp. 94-6. En el caso del Sistema Interamericano de Derechos Humanos es importante notar que desde temprano se advirtió esta doble faz de la libertad de expresión, y su especial conexión con el ideal democrático. Así, la Corte ha afirmado que "[1]a libertad de expresión es una piedra angular en la existencia misma de una sociedad democrática. Es indispensable para la formación de la opinión pública... para que los partidos políticos, los sindicatos, las sociedades científicas y culturales, y en general, quienes deseen influir sobre la colectividad puedan desarrollarse plenamente. Es, en fin, condición para que la comunidad, a la hora de ejercer sus opciones, esté suficientemente informada". Costa Rica, 13 de noviembre de 1985, Opinión Consultiva sobre "La Colegiación Obligatoria de Periodistas" OC-5/85, par. 70. Útil es notar, además, que tras los énfasis en una u otra faz se esconden dos concepciones distintas de la democracia. Véase, Fiss, O., La Ironía de la Libertad de Expresión, op. cit., pp. 15-41.

${ }^{104}$ Y que, además, como ha sugerido Post, abre una esfera en que los intereses personales (individuales) están constantemente reconciliándose con la autonomía colectiva. Post, R., "Subsidized Speech", en Yale Law Journal, Vol. 106, 1996, p. 153.

105 Dworkin, R., Freedom's Law: The moral reading of the American Constitution, Oxford University Press, Nueva York, pp. 200.

106 Raz, J., La Ética en el Ámbito de lo Público, Gedisa, Barcelona, 2001, p. 165.

${ }^{107}$ Barendt, Freedom of Speech, op. cit., pp. 496-7; Heck, E. y Ringelstein, A., "The Burger Court and the Primacy of Political Expression", en Western Political Quarterly, No 40, 1987, p. 415-16 y 420. 
capacitadas para escuchar opiniones peligrosas u ofensivas [en concepto del Estado] que los puedan persuadir" ${ }^{08}$.

Sin embargo, la distinción anterior no es suficiente. Es preciso, además, advertir que es justamente esa igual agencia moral que se nos reconoce en tanto miembros de una comunidad la que debe llevarnos a concebir el discurso público como uno de carácter no elitista. El discurso público, mirado desde esta óptica, asume que la libertad de expresión sirve un importante valor político ${ }^{109}$ : el de permitir que las personas participen libremente en la formación de la opinión pública, frente a la cual el Estado es sensible ${ }^{110}$. Esa opinión pública, a la que podemos contribuir en tanto agentes morales a los que se nos reconoce un lugar en la comunidad, trasciende el discurso (exclusivamente) político para abarcar otras formas de expresiones que también contribuyen a la formación de esa opinión y que, por lo mismo (en tanto el Estado es sensible a ella), amplía el ideal de autogobierno ${ }^{111}$.

Por controversiales que nos parezcan esas expresiones ${ }^{112}$, la protección de la libertad de discurso se justifica en la independencia que estos 'nuevos' discursos tienen respecto del control de las normas o valores que endosen los jueces o decisores ${ }^{113}$. Por ello es que el discurso que prima facie aparece como irrelevante desde un punto de vista político, como puede ser un desfile de modas o la vida de alguna celebridad, permite "clarificar los valores y compromisos públicos”. Decir que el arte no puede tomarse en serio y que por ese solo hecho no se censura una obra, equivale a afirmar, en primer término, que el discurso público puede configurarse solo con ciertas expresiones que los jueces calificarán como serias ${ }^{114}$. En efecto, según fluye de las decisiones analizadas, se suele minimizar el papel del arte en el entendido de que existe una realidad 'objetiva' a la que apelan los decidores $^{115}$ (la vida de Jesucristo, las proezas de Prat, el funcionamiento del Vaticano

108 Dworkin, Freedom's Law, op. cit., p. 201.

109 O bien público, como sugiere Raz, op. cit.

110 Post, R., “A Progressive Perspective on Freedom of Speech”, en Balkin, J. y Siegel, R., The Constitution in 2020, Oxford University Press, Nueva York, 2009, pp. 182-3.

${ }^{111} \mathrm{La}$ exclusión de algunos de la posibilidad de participar de la formación del discurso público, por ejemplo, reclamando la existencia de verdades objetivas que el excluido es incapaz de comprender, supone configurar una práctica política opresiva en tanto niega su condición de igual (agente moral de una comunidad que previamente debe reconocerlo como uno-igual). Atria, F., "La verdad y lo político (I). La verdad y su dimensión constitutiva", en Persona y Sociedad, Universidad Alberto Hurtado, Vol. XXIII, N ${ }^{\circ}$, abril 2009 , p. 27.

112 Asumo con Schauer que el discurso, en sí mismo, no es autorreferente sino que, en cambio, afecta a los otros. Schauer, F., Free speech: a philosophical enquiry, Cambridge University Press, Nueva York, 1982, p. 10 .

113 Post, "The Constitucional Concept of Public Discourse”, op. cit., p. 626.

${ }^{114}$ Lo que afecta, de paso, las posibilidades de reconocimiento simbólico de ciertos estilos de vida. Raz, op. cit., pp. 168-74.

115 El término "apelan", acá, está tomando en el sentido de Atria, "La verdad y lo político", op. cit., pp. 27-32. 
o la historia de la Virgen María), a la que el arte no contribuye ${ }^{116}$. En segundo lugar, los argumentos que nuestras instancias de decisión han esgrimido implican que el arte no recibe protección constitucional en tanto expresión, sino que solo no es censurado en tanto nadie se lo toma en serio. El riesgo es que, tal como lo afirma Rodrigo Correa en su análisis de la obra $\operatorname{Prat}^{117}$, si alguien comienza a tomarse en serio el arte -0 , mejor dicho, si los jueces consideran que el arte es bueno o serio- las cortes comiencen a censurarlo porque nunca le garantizaron protección constitucional vigorosa.

\section{Conclusiones}

Nuestras instancias decisorias en materia de libertad de creación artística han actuado como los jueces del 'mito judicial' de Frank. Han preferido cerrar los ojos a la realidad normativa de la libertad de expresión para evitar las consecuencias que se siguen de reconocer una libertad vigorosa. Quienes deciden esos casos prefieren colocar la culpa de parte del artista, sin entender que la misma libertad de expresión es la que los faculta para hacer lo que hacen: algo más que solo "piezas teatrales intrascendentes y de escasa proyección”, como sostuvo la Corte Suprema en Prat-respondiendo preguntas que nadie formuló.

Las instancias de decisión en materia de libertad de creación artística y libertad de expresión en Chile descansan sus decisiones en lo que asumen son visiones 'objetivas' y, por lo mismo, incapaces de ser disputadas. Lo que el análisis de los cuatro casos detallados más arriba nos evidencia es que la defensa de las obras no radica en la comprensión de una vigorosa libertad de expresión, sino que en un conformismo ${ }^{118}$ con esas concepciones de la vida que nuestras instancias de decisión endosan como 'lo objetivo' y que el arte es siquiera capaz de traer al frente de la discusión.

Los problemas de esta aparente protección, he sugerido, se explican, en particular, por la ausencia de una teoría política sobre el valor de la libertad de expresión y, lo que es más lamentable, se proyectan al futuro. Al tratarse solo de una aparente protección -queriendo decir con esto que no depende de la fuerza de la libertad de expresión- es débil. Y porque es débil es sencilla de derribar.

${ }^{116}$ Aunque valdría la pena preguntarse si esas mismas realidades objetivas no se han construido en torno a otras expresiones artísticas que no pugnan con los valores que defienden recurrentes y decidores. Greenawalt, K., Religion and the Constitution Vol. 2: Establishment and Fairness, Princeton University Press, Nueva Jersey, 2008, capítulo 5 (sobre el despliegue de obras religiosas en lugares públicos y su efecto simbólico).

117 Véase nota 74.

118 Sunstein, C., Why Societies Need Dissent, Harvard University Press, Cambridge, 2003, p. 1 ("Unchecked by dissent, conformity can produce disturbing, harmful, and sometimes astonishing outcomes"); también Heck y Ringelstein, “The Burger Court”, op. cit., p. 422. 


\section{BIBLIOGRAFÍA}

Alexy, R., Teoría de los Derechos Fundamentales, Centro de Estudios Constitucionales, Madrid, 2002.

Anguita, P., El derecho a la Información en Chile, Editorial LexisNexis, Santiago, 2005.

Atria, F., "La verdad y lo político (I). La verdad y su dimensión constitutiva", en Persona y Sociedad, Universidad Alberto Hurtado, Vol. XXIII, N 1, abril 2009.

Barendt, E., Freedom of Speech, Oxford University Press, Oxford, 2007 (2a ed.).

Castillo, E., Puño y Letra: Movimiento Social y Comunicación Gráfica en Chile, Ocho Libros Editores, Santiago, 2006.

CEA, J., Derecho Constitucional Chileno, Tomo II: Derechos, Deberes y Garantías, Ediciones Universidad Católica de Chile, Santiago, 2004.

Cea, J., Tratado de la Constitución de 1980. Características Generales. Garantías Constitucionales, Editorial Jurídica de Chile, Santiago, 1988.

Center for Justice and International Law, Protection of the Right to the Freedom of Expression in the Inter-American System, Cejil, San José, 2006.

Ciudad, J., 1992. "La Oleada Demoníaca”, en Revista Rockaxis, No 65 (Marzo), 2008.

Contesse, J., "Responsabilidad por la Interpretación Constitucional", en Revista Derecho y Humanidades $\mathrm{N}^{\circ} 11,2005$.

Contesse, J., "Reglas y Principios en Chile: ¿Jerarquía entre los Derechos Constitucionales?”, en Anuario de Filosofía Jurídica y Social, No 20, 2002.

Correa, R., "Derechos Constitucionales", en Revista de Derecho Universidad Adolfo Ibáñez, $\mathrm{N}^{\circ} 1$, 2004.

Dworkin, R., Freedom's Law: The moral reading of the American Constitution, Oxford University Press, Nueva York.

Evans de la Cuadra, E., Los Derechos Constitucionales, Tomo II, Editorial Jurídica de Chile, Santiago, 1999.

Evans de la Cuadra, E., Los Derechos Constitucionales, Tomo III, Editorial Jurídica de Chile, Santiago, 1999.

Fallon, Jr, R., The Dynamic Constitution. An Introduction to American Constitucional Law, Cambridge University Press, Nueva York, 2004.

Fiss, O., La Ironía de la Libertad de Expresión, Gedisa, Barcelona, 1999.

Frank, J., Derecho e Incertidumbre, Fontamara S.A., México D.F., 1991.

Frank, J., "Law and the Modern Mind", en Cerda, C. (ed.), Razonamiento Judicial, Universidad Diego Portales, Santiago, 1995.

Goodrich, L., "Freedom of Expression in the Arts I", en Art Journal, No 25, 1965.

Greenawalt, K., Religion and the Constitution, Vol. 2: Establishment and Fairness, Princeton University Press, Nueva Jersey, 2008.

Hancher, M., “Dead Letters: Wills and Poems”, en Texas Law Review, No 60, 1982.

Heck, E. y Ringelstein, A., “The Burger Court and the Primacy of Political Expression”, en Western Political Quarterly, No 40, 1987.

Human Rights Watch, Los Limites de la Tolerancia: Libertad de Expresión y Debate Público en Chile, Lom Ediciones, Santiago, 1998.

Huneeus, C., La Guerra Fría Chilena: Gabriel González Videla y la Ley Maldita, Editorial Debate, Santiago, 2009.

Lovera, D., "El Interés Público como Estándar. Libertad de Expresión y Vida Privada”, en González, F. (ed.), Libertad de Expresión, Universidad Diego Portales, Santiago, 2006.

Marx, K., El 18 Brumario de Luis Bonaparte, Prometeo Libros, Buenos Aires, 2003. 
Nietzsche, F., Humano, demasiado bumano, Edaf, Madrid, 1984.

Nino, C. S., La Constitución de la Democracia Deliberativa, Gedisa, Barcelona, 1997.

Post, R., "A Progressive Perspective on Freedom of Speech", en Balkin, J. y Siegel, R., The Constitution in 2020, Oxford University Press, Nueva York, 2009.

Post, R., "Subsidized Speech", en Yale Law Journal, Vol. 106, 1996.

Post, R., "The Constitucional Concept of Public Discourse: Outrageous opinion, Democratic Deliberation, and Hustler Magazine v. Falwell”, en Harvard Law Review, No 3 Vol. 103, enero 1990.

Putnam, H., Las Mil Caras del Realismo, Editorial Paidós, Barcelona, 1994.

Raz, J., La Ética en el Ámbito de lo Público, Gedisa, Barcelona, 2001.

Ruiz-Tagle, P., “Apuntes sobre Libertad de Expresión y Censura en Chile”, en Ruiz-Tagle, P., Derecho, Justicia y Libertad: Ensayos de derecho chileno y comparado, Fontamara S.A., México D.F., 2002.

Schauer, F., Free speech: a philosophical enquiry, Cambridge University Press, Nueva York, 1982.

Schwabe, J. (comp.), Cincuenta Años de Jurisprudencia del Tribunal Constitucional Alemán, Konrad Adenauer Siftung, Montevideo, 2003.

Sunstein, C. R. et al., Are Judges Political? An Empirical Analysis of the Federal Judiciary, Brookings, Washington D.C., 2006.

Sunstein, C. R. et al., Why Societies Need Dissent, Harvard University Press, Cambridge, 2003.

Universidad Diego Portales, Informe Anual sobre Derechos Humanos 2007, Universidad Diego Portales, Santiago, 2007.

Universidad Diego Portales, Informe anual sobre Derechos Humanos 2003, Santiago, Universidad Diego Portales, 2003.

Verdugo, M., Pfeffer, E. y Nogueira, H., Derecho Constitucional, Tomo I, Editorial Jurídica de Chile, Santiago, 1999.

Vial T., "El Derecho a la Libertad de Creación Artística en la Constitución", en González, F. (ed.), Libertad de Expresión en Chile, Universidad Diego Portales, Santiago, 2006.

Vial T., "La Libertad de Creación Artística. Un nuevo derecho constitucional", en Informe de Investigación, $\mathrm{N}^{\circ} 19$, Centro de Investigaciones Jurídicas, Universidad Diego Portales, Santiago, 2004

Vitale, L., Historia de la Censura en Chile, en Jones, D., Censorship: An Encyclopaedia, Fitzroy Dearborn Publishers, Londres, 2001.

Vivanco, A., Curso de Derecho Constitucional, Tomo II: Aspectos Dogmáticos de la Carta Fundamental de 1980, Ediciones Universidad Católica de Chile, Santiago,

Waldron, J., The Dignity of Legislation, Cambridge University Press, Cambridge, 1999.

ZÚÑIGA, A., "La libre formación del pensamiento en el caso 'La Última Tentación de Cristo'”, en González, F. (ed.), Libertad de Expresión en Chile, Universidad Diego Portales, Santiago, 2006. 